\title{
Managing Specialty Medication Services Through a Specialty Pharmacy Program: The Case of Oral Renal Transplant Immunosuppressant Medications
}

\author{
Suzanne Tschida, PharmD, BCPS; Saad Aslam, PhD; Tanvir T. Khan, MS; Brett Sahli, PharmD; \\ William H. Shrank, MD, MSHS; and Lincy S. Lal, PhD, PharmD
}

\begin{abstract}
BACKGROUND: Immunosuppressive medication therapy after organ transplantation is essential for preventing transplant rejection and minimizing the need for re-transplantations. Nonadherence to immunosuppressant therapy has been identified as a major risk factor for acute complications and allograft rejection, as well as late graft rejection, and a return to dialysis after failed renal transplantation, leading to an increase in health care costs and potentially even death.

OBJECTIVE: To evaluate clinical and economic outcomes of a mandatory transplant specialty pharmacy program implemented for the membership of a national commercial health plan for post-renal transplantation patients, as compared with membership using traditional retail pharmacy services. This program was delivered by a designated specialty pharmacy, which met requirements for contracted rates and provision of clinical programs and services.
\end{abstract}

METHODS: The study is a 1-year retrospective claims analysis after the implementation of a transplant specialty pharmacy program that, in addition to medication dispensing, includes adherence and clinical management programs, patient education, and counseling services provided by transplant pharmacology experts. Renal transplant patients using the specialty pharmacy program were matched to those using retail pharmacies utilizing a propensity score-matching technique based on logistic regression. Primary outcomes were financial, which included pharmacy medication costs, medical inpatient and outpatient costs, and overall health care costs. Patient adherence to transplant medication therapy and health care resource utilization were also evaluated. One-year outcomes postspecialty pharmacy program implementation were compared between the two groups with t-tests for continuous variables and chi-square tests for nominal variables.

RESULTS: After propensity score matching, 519 patients were identified per group for analysis. Baseline parameters were similar between the two groups. The mean total health care cost during 1 year of follow-up was $13 \%$ lower in the specialty pharmacy program group ( $\$ 24,315$ vs. $\$ 27,891, P=0.03)$. Similarly, the mean transplant-related medical cost was $30 \%$ lower in the specialty pharmacy program group $(\$ 5,960$ vs. $\$ 8,486$; $P=0.04$ ), with lower cost, although not statistically significant, in both the dialysis-related and the nondialysis-related costs. The transplant-related office visit costs ( $\$ 395$ vs. $\$ 555 ; P=0.04$ ) were significantly lower for the specialty pharmacy program cohort, while the inpatient and outpatient transplant-related costs were lower but not statistically significant in the specialty program. The weighted medication procession ratio (MPR) was higher ( 0.87 vs. $0.83 ; P<0.0001$ ); the number of patients with a medication gap or who discontinued was lower (65 vs. $142 ; P<0.0001)$ in the specialty pharmacy program members than in the retail pharmacy members.

CONCLUSIONS: This specialty pharmacy program is associated with lower transplant-related medical costs and lower overall health care costs, as well as higher transplant medication adherence within the first year of evaluation. The positive impact of health plan program design and coordinated care and oversight by transplant pharmacology experts in a specialty pharmacy program has implications for the current health care reform and requires more research.

J Manag Care Pharm. 2013;19(1):26-41

Copyright $\odot 2013$, Academy of Managed Care Pharmacy. All rights reserved.

\section{What is already known about this subject}

- Medication nonadherence in the transplant population ranges from 20\%-70\%, depending on differences in measurement method utilized and study populations. Reasons for nonadherence include patient-related components such as misunderstanding the importance of immunosuppressive therapy or how to take the medication regimen, forgetfulness, lack of communication and follow-up with the medical team, and depression. Medication-related components of nonadherence include a high pill burden, high frequency and severity of drug interactions, and adverse effects. Complications due to nonadherence can result in increased physician visits and inpatient hospitalization stays and, in cases of kidney transplantation failures, re-initiation of dialysis, all culminating in increased overall health care costs.

- Specialty pharmacies aim to reduce variability in pharmaceutical care delivery, improve appropriate medication use and the quality of care, and manage adverse effects that are inherent with transplant pharmacotherapy. Specialty pharmacies, in addition to providing basic dispensing and counseling services, may use specialty-trained nurses and pharmacists to continually engage and educate transplant recipients on strategies to improve the success of their therapies and patency of their transplanted grafts. Studies in Medicare and in tertiary care institution-based transplant specialty pharmacy programs indicate that patient education, adherence oversight, and clinical management services positively influence medication adherence, total health care costs, and patients' quality of life. In one study by Chisholm-Burns (2008), patients at a tertiary care institution after 1 year of followup with clinical pharmacy services versus control group had a higher mean adherence rate compared with those in the control group (96.1\% vs. $81.6 \%$; $P<0.001)$. Additionally, they had a mean total cost of $\$ 2,614$ less per patient than the control group. 


\section{Managing Specialty Medication Services Through a Specialty Pharmacy Program: The Case of Oral Renal Transplant Immunosuppressant Medications}

What is already known about this subject (continued)

- Specialty pharmacy care management programs have also shown positive outcomes in multiple sclerosis (MS), human immunodeficiency virus (HIV)/acquired immunodeficiency syndrome (AIDS), oral oncology, and rheumatoid arthritis (RA) patients. In patients with MS, specialty pharmacy services, including a disease therapy management program, improved medication adherence and persistence among participants compared with patients being serviced in a nonspecialty pharmacy setting. In patients with HIV/AIDS, specialty pharmacies have documented adherence improvements measured as the mean proportion of days covered (PDC; $74.1 \%$ specialty pharmacy vs. $69.2 \%$ retail pharmacy; $P<0.0001$ ). In oncology patients, patients in the specialty pharmacy group were more adherent compared with patients in a nonspecialty pharmacy group as evidenced by a weighted medication possession ratio (MPR) of 0.66 versus 0.58 $(P<0.001)$. Additionally, the overall mean total costs per patient were $13 \%$ lower in the specialty pharmacy group during the follow-up period. In RA patients, mean PDC was documented to be higher at 0.81 for specialty pharmacy patients versus 0.60 for the community pharmacy patients. In a separate study by Barlow et al. (2012), specialty pharmacy patients with RA exhibited significantly lower medical costs over a period of 3 years versus retail pharmacy patients, although the pharmacy costs were higher in the specialty groups due to higher medication adherence.

\section{What this study adds}

- We compared the effectiveness of a transplant specialty pharmacy program implemented by a large commercial health plan through a designated specialty pharmacy to improve post-renal transplant care as compared with services through retail pharmacies in a similar population. The mean total cost per patient in the first year of follow-up was $13 \%$ lower in the specialty pharmacy program group $(\$ 24,315$ vs. $\$ 27,891$, difference $=-\$ 3,576$; $P=0.03)$. Similarly, the mean transplant-related medical cost was $30 \%$ lower in the specialty pharmacy program group ( $\$ 5,960$ vs. $\$ 8,486$, difference $=-\$ 2,525 ; P=0.04$ ).

- The weighted MPR for oral immunosuppressive therapy medications was higher in the specialty pharmacy program members than in the retail pharmacy members ( 0.87 vs. 0.83 , respectively; $P<0.0001)$. The weighted MPR is an innovative approach to measuring adherence and takes into account therapy augmentation, switching, and concomitant use of medications. The mean number of oral transplant prescriptions dispensed per patient was higher in the specialty pharmacy program group than in the retail pharmacy group (18.67 vs. 17.90, respectively; difference $=0.77 ; P<0.05)$.

- Both nondialysis-related costs $(\$ 5,232$ vs. $\$ 6,739 ; P=0.10)$ and dialysis-related costs ( $\$ 728$ vs. $\$ 1,747 ; P=0.08$ ) were nonsignificantly lower in the specialty group. Additionally, dialysis-related and nondialysis-related medical outcomes during the follow-up were evaluated. There was a significant difference in the mean number of members with dialysis-related inpatient hospital stays between the two groups ( 0.02 vs. $0.04 ; P=0.03$ ), leading to lower, although nonsignificant, mean dialysis-related inpatient hospital count and mean dialysis-related inpatient hospital cost in the specialty pharmacy program group.

I mmunosuppressive medication therapy after organ transplantation is essential for preventing transplant rejection. Adherence to oral immunosuppressive therapy is crucial for the success of maintaining the transplanted graft. Prompt management of complications and mitigation of transplant medication adverse events are critical to ensure that patients remain adherent to their transplant medications. Unfortunately, nonadherence to immunosuppressive therapy has been reported in $20 \%-70 \%$ of the transplant population; this wide range is based on variation in adherence measures and study populations. ${ }^{1-7}$ Nonadherence rates with immunosuppressive therapy increase over time since the transplant occurred. ${ }^{8}$ Reasons for nonadherence include such patient-related components as understanding the need for immunosuppressive therapy, misunderstanding of the medication regimen, forgetfulness, lack of communication and follow-up with the medical team, and depression. Medication-related components of nonadherence include a high pill burden, high frequency and severity of drug interactions, and adverse effects. 1,2,9,10

Nonadherence has been identified as a major risk factor for acute complications and allograft rejection, as well as for late graft rejection, complications, and even death. Complications due to nonadherence can result in increased physician visits and inpatient hospitalization stays and, in cases of kidney transplantation failures, re-initiation of dialysis, all culminating in increased overall health care costs. ${ }^{11-15}$

Immunosuppressant therapy is costly, with an annual medication regimen expense of approximately $\$ 30,000$ during the first year after transplantation and $\$ 15,000$ every year thereafter. ${ }^{16,17}$ In order to improve quality of care and possibly reduce overall medical costs, health plans are looking increasingly to specialty pharmacy programs and/or specialty pharmacies to address the challenges of managing transplant patients taking oral immunosuppressive therapy. Specialty pharmacies aim to reduce variability in pharmaceutical care delivery, improve appropriate medication use and the quality of care, and manage adverse effects that are inherent with transplant pharmacotherapy. ${ }^{.}$Specialty pharmacies, in addition to providing basic dispensing and counseling services, may use specialty-trained nurses and pharmacists to continually engage and educate transplant recipients on strategies to improve the 


\section{Managing Specialty Medication Services Through a Specialty Pharmacy Program: The Case of Oral Renal Transplant Immunosuppressant Medications}

success of their transplant medication therapies and patency of their grafts. Topics may include how to maintain maximal adherence by developing good medication-taking skills; using medication reminder resources such as charts, alarms, or special medication containers; and teaching patients how to anticipate and manage side effects. The goal is for members to more actively engage in the management of their care. ${ }^{18,19}$ Studies in Medicare and in tertiary care institution-based transplant specialty pharmacy programs indicate that patient education, adherence oversight, and clinical management services positively influence medication adherence, total health care costs, and patients' quality of life. ${ }^{1,17}$ However, little is known about the costs and benefits of specialty pharmacy programs in the commercial transplant population. Accordingly, we compared the effectiveness of a transplant specialty pharmacy program implemented by a large commercial health plan through a designated specialty pharmacy to improve post-renal transplant care with the services provided through retail pharmacies in a similar population.

\section{Methods}

\section{Intervention}

In August 2007, UnitedHealthcare Pharmacy implemented a mandatory oral immunosuppressant transplant medication specialty pharmacy program for its commercial employer group plans. The program required the contracted specialty pharmacy to provide clinical expertise and patient education in transplant medications and comorbid conditions, a monthly proactive adherence program including refill reminders, and adherence screening and interventions with the members and physicians if nonadherence was detected through the interview of patients' medication-taking habits at the point of dispensing, using a modified adherence screening from a validated adherence questionnaire. ${ }^{20}$ Additionally, a transplant clinical management program of telephonic clinical counseling sessions was required to provide extensive patient education, assessment of disease-specific parameters, pharmaceutical care interventions, and provider outreach and referral to health resources. The insurance coverage was offered through employers and consisted of both self-insured and fully insured employers.

The specialty pharmacy program had requirements for contracted medication reimbursement rates, staff expertise, operational services, and clinical programs that were met by the contracted specialty pharmacy. Similar options for medical benefits and contracted rates for medical services were available to the two groups. The interventional adherence program included reminder calls to the member to coordinate medication refills, with assessment during the call for medication nonadherence in the past 30 days of therapy. If nonadherence was suspected, clinical counseling with specialty-trained pharmacists was provided to address any adherence-related issues through patient education and support strategies, identification of financial assistance opportunities, and/or engagement with the physician. If the patient did not refill the immunosuppressive therapy medication and was not able to be reached after 3 attempts, the physician was contacted regarding the potential adherence concern.

Educational information about transplantation and comorbid disease states, transplant medications including side-effect management tips, and the importance of medication adherence were included as part of the extensive member education materials provided over the course of care through the specialty pharmacy. Additionally, clinical management consultation calls with specialty clinicians trained in transplant pharmaceutical care were offered. Consultations were offered monthly for the first 3 months and then approximately every 3 months thereafter while the member was in the program to assess the member's clinical status and provide pharmaceutical care interventions and additional education as needed.

Patients were advised to contact their specialty pharmacists with questions as needed, and this support was available 24/7. When appropriate, the pharmacists engaged in communication with the health care providers about their intervention recommendations or immunosuppressive therapy clinical concerns that were identified in the consultations. Figure 1 summarizes the flow of interactions between post-renal transplant patients and their specialty pharmacy programs.

For those employer groups that enrolled in the specialty pharmacy program, one specialty pharmacy vendor, meeting the above program requirements, was designated as the sole provider of prescriptions for the specific oral immunosuppressive therapy; however, patients could have up to 2 grace fills at a network retail pharmacy during their transition to the specialty pharmacy. Patients in employer groups not enrolled in the specialty pharmacy program continued to obtain oral immunosuppressive therapy through a network of retail pharmacies.

\section{Data and Sample Selection}

The data source was an administrative claims database for approximately 14 million UnitedHealthcare enrollees. Data included prescription drug, medical, and facility claims information. The claims were de-identified and made to comply with the provisions of the Health Insurance Portability and Accountability Act (HIPAA) of 1996.

Patients with a history of renal transplantation during the baseline period (ICD-9-CM [International Classification of Diseases, Ninth Revision, Clinical Modification]: diagnosis code V42.0 [kidney replaced by transplant], procedure code 55.69 [other kidney transplantation]; CPT [Current Procedural Terminology] codes 50360, 50365 [renal allotransplantation]) who received pharmacy and medical benefits through UnitedHealthcare and filled 1 or more prescriptions for an oral transplant study drug between August 1, 2007, and December 


\section{Managing Specialty Medication Services Through a Specialty Pharmacy Program: The Case of Oral Renal Transplant Immunosuppressant Medications}

\section{FIGURE 1 An Overview of Specialty Pharmacy Program Flow}

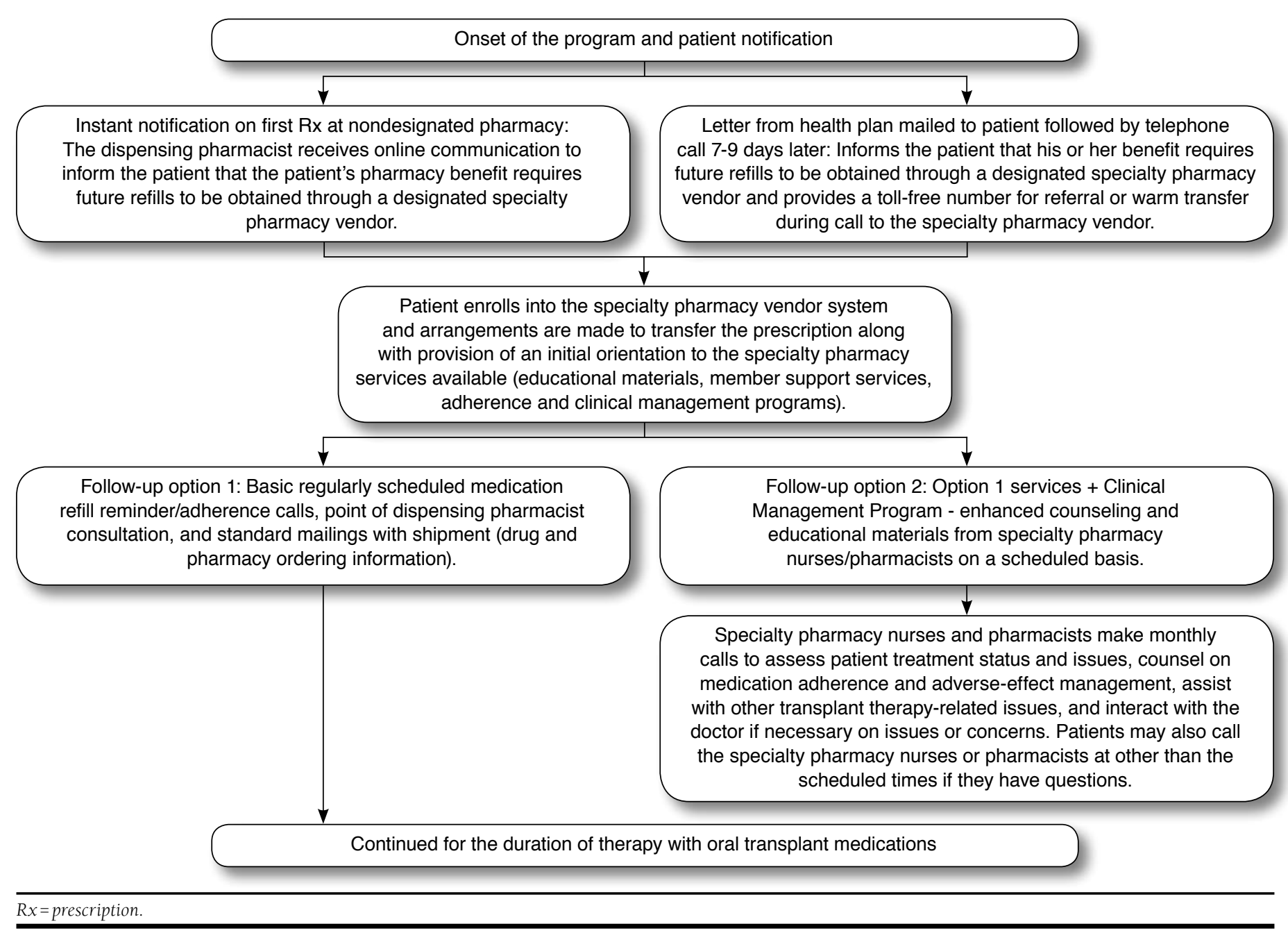

31, 2007, were included in the study (see Appendix A for study drug list). In order to focus on patients with consistent prognosis and associated costs, we concentrated on kidney transplant members because the kidney is the most commonly transplanted organ and has more than a 40\% 10-year graft survival rate in recipients of living or deceased donations. ${ }^{21}$ During the identification period post-implementation, each patient was assigned an index date (the first immunosuppressive drug prescription fill date) and an index drug (the immunosuppressive drug(s) at this fill date). Study patients were required to be continuously enrolled for at least 1 year prior to the index date (baseline period) and for 1 year afterward (follow-up period). The first 2 prescriptions were dropped for each patient, regardless of where they were filled, to account for the transition period during which they were permitted to use any pharmacy. Each patient was then assigned to the specialty pharmacy program or to the retail cohort.
To account for continuity of participation, patients who filled $80 \%$ or more of their oral transplant prescriptions from the contracted specialty pharmacy were classified as specialty pharmacy patients, and those filling $80 \%$ or more of their oral transplant prescriptions from retail pharmacies were assigned to the retail pharmacy cohort. Those patients who did not meet either criterion were omitted from the study (13\% of the study population). Specialty pharmacy program group participation and cohort assignment adherence were also assessed; in 97\% of employer groups, our assignment criteria led to assignment of all patients within a given group to either a specialty pharmacy program or retail cohort. In other words, we found variability in member cohort assignment within employer groups in only $3 \%$ of employers, indicating that there was little selection bias due to patient choice or employer choice. The details of sample attrition are shown in Figure 2 and are discussed further in the Results section. 


\section{Managing Specialty Medication Services Through a Specialty Pharmacy Program: The Case of Oral Renal Transplant Immunosuppressant Medications}

\section{FIGURE 2 Sample Size Determination}

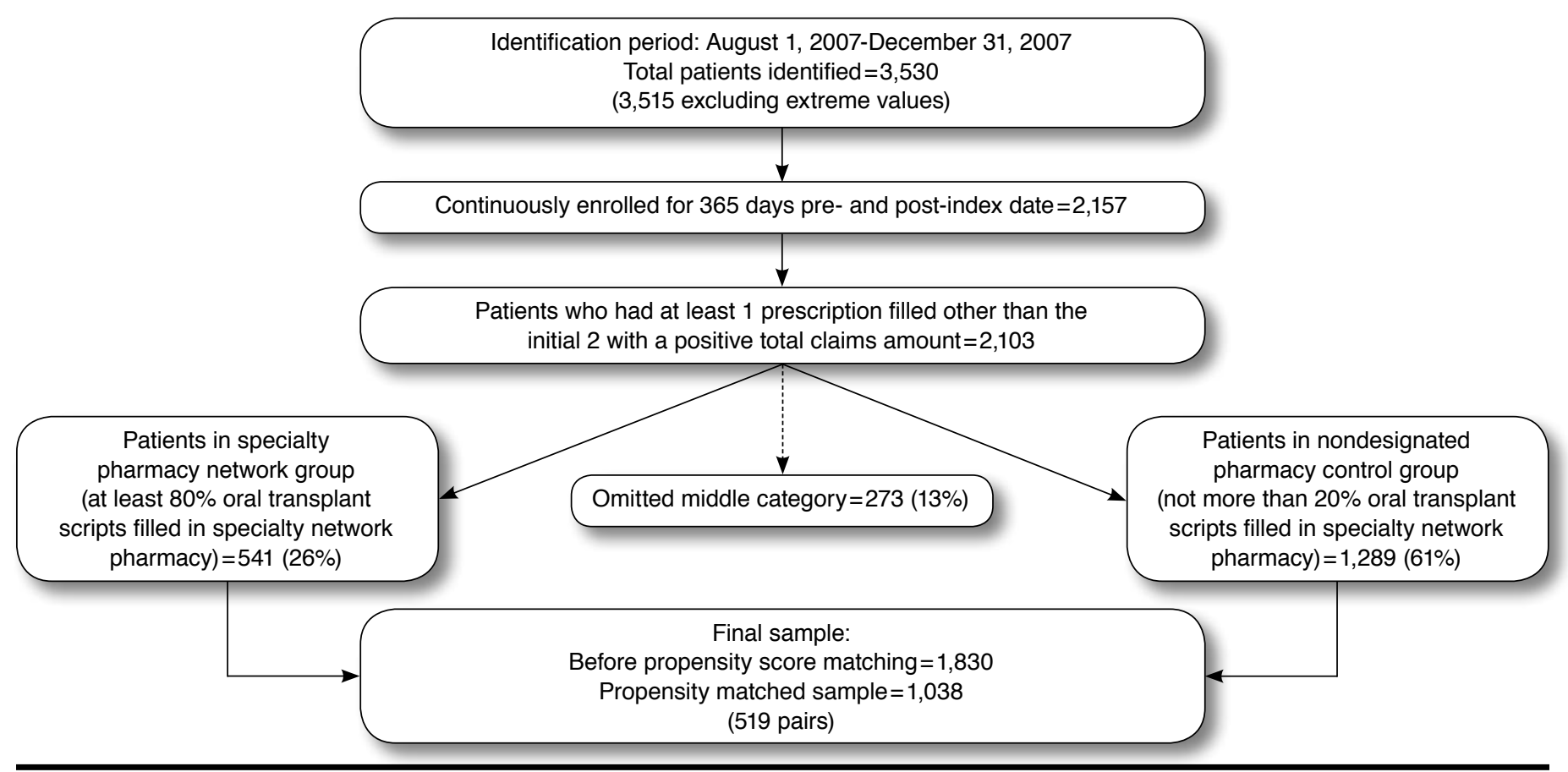

\section{Statistical Analysis}

A retrospective matched cohort study was designed to compare differences in health care costs and health services utilization between patients with a medical history of renal transplantation who used the specialty pharmacy program and those who used retail pharmacies for oral immunosuppressive therapy medication services. The primary outcome measures were financial and included overall costs (pharmacy and medical), total outpatient costs, total medical costs (inpatient, outpatient hospital and office, and emergency room [ER]), and pharmacy costs. Physician, facility, and pharmacy claims were utilized to collect the costs and included paid amount, copay amount, deductible, coinsurance, and for pharmacy ancillary amount. Members having extreme mean total costs (values over population mean, plus 5 standard deviations) were dropped from the study to control for outlier impact. Secondary outcome measures included clinical resource utilization such as hospitalizations, inpatient and outpatient hospital visits, and ER visits. Additionally, transplant-specific total medical and pharmacy costs; transplant-specific resource utilization outcomes, such as transplant-related inpatient visits, outpatient visits, physician office visits, and ER visits; transplant-related complications; and dialysis and nondialysis resource utilization and costs (see Appendices A and B for specific transplant-related medical and drug codes) were analyzed. Place of service and revenue codes were utilized to determine type of service for inpatient, outpatient, physician office, and ER visits. Additionally, we evaluated medication adherence and persistence for each patient using 5 methods: (1) the number of prescriptions filled; (2) weighted medication possession ratio (MPR), which has been previously utilized in the oncology setting ${ }^{22}$ (see Appendix C for methodology); (3) medication gaps (MG), defined as a period of at least 60 days without oral transplant medication in the post-period but followed by a re-initiation of immunosuppressive therapy medication before the end of the post-period; (4) discontinuation (DC), defined as any gap of at least 60 days or more without oral transplant medications that is never followed by a re-initiation of therapy within the study period; and (5) either an MG or DC. There are many ways to calculate adherence and persistence, and we wanted to see if the results are consistent between the different methods. Additionally, all 90 -day supply fills (8.4\% in the retail cohort) were normalized to a 30-day supply for mean fills comparison.

In order to control for unmeasured confounding, the 2 cohorts were balanced using propensity score matching. The probability of being in either of the cohort groups, or propensity score, was derived from a logistic regression, which was then used to construct matched samples from the 2 cohorts. ${ }^{23-28}$ We used a one-on-one greedy matching technique with 3 units matched at 0.005 to derive the propensity score matched-pair sample and to reduce bias due to incomplete and inexact matching. ${ }^{29}$ The logistic regression used patients' 


\section{Managing Specialty Medication Services Through a Specialty Pharmacy Program: The Case of Oral Renal Transplant Immunosuppressant Medications}

\section{TABLE 1 Baseline Descriptive Statistics of Renal Transplant Patients ${ }^{a}$}

\begin{tabular}{|c|c|c|c|c|c|c|c|c|}
\hline & \multicolumn{4}{|c|}{ Before Propensity Score Matching } & \multicolumn{4}{|c|}{ After Propensity Score Matching } \\
\hline & \multirow{2}{*}{$\begin{array}{c}\text { Retail }^{b} \\
(1)\end{array}$} & \multirow{2}{*}{$\begin{array}{c}\text { Specialtyc } \\
(2)\end{array}$} & \multirow{2}{*}{$\begin{array}{l}\text { Difference } \\
(1-2)\end{array}$} & \multirow[b]{2}{*}{$P$ Valued } & \multirow{2}{*}{$\frac{\text { Retail }^{b}}{(3)}$} & \multirow{2}{*}{$\begin{array}{c}\text { Specialty }^{\mathrm{c}} \\
(4)\end{array}$} & \multirow{2}{*}{$\begin{array}{l}\text { Difference } \\
\quad(3-4)\end{array}$} & \multirow[b]{2}{*}{$P$ Valued } \\
\hline & & & & & & & & \\
\hline $\mathrm{N}$ & 1,289 & 541 & & & 519 & 519 & & \\
\hline Age & 50.16 & 49.85 & 0.31 & 0.64 & 49.78 & 49.78 & 0.01 & 0.99 \\
\hline Female & 0.40 & 0.40 & 0.01 & 0.84 & 0.38 & 0.39 & -0.01 & 0.70 \\
\hline Charlson score & 2.43 & 2.23 & 0.20 & 0.03 & 2.22 & 2.26 & -0.04 & 0.70 \\
\hline New starts: no baseline transplant Rx & 0.06 & 0.04 & 0.02 & 0.30 & 0.03 & 0.04 & 0.00 & 0.91 \\
\hline \multicolumn{9}{|l|}{ First baseline transplant $\mathrm{Rx}$} \\
\hline Quarter 1 & 0.81 & 0.84 & -0.03 & & 0.84 & 0.84 & 0.01 & \\
\hline Quarter 2 & 0.07 & 0.07 & 0.00 & & 0.06 & 0.07 & -0.01 & \\
\hline Quarter 3 & 0.04 & 0.04 & 0.00 & & 0.05 & 0.04 & 0.01 & \\
\hline Quarter 4 & 0.02 & 0.02 & 0.01 & & 0.01 & 0.02 & 0.00 & \\
\hline $\begin{array}{l}\text { Complications of transplanted organ, kidney } \\
\text { (ICD-9-CM 996.81) }\end{array}$ & 0.32 & 0.29 & 0.02 & 0.34 & 0.32 & 0.29 & 0.02 & 0.35 \\
\hline Patients on dual therapy & 0.37 & 0.40 & -0.03 & 0.29 & 0.41 & 0.39 & 0.03 & 0.38 \\
\hline Geographical region & & & & $<.001$ & & & & 0.99 \\
\hline New England & 0.04 & 0.01 & 0.04 & & 0.01 & 0.01 & 0.01 & \\
\hline Mid Atlantic & 0.07 & 0.01 & 0.06 & & 0.01 & 0.02 & 0.00 & \\
\hline East North Central & 0.09 & 0.19 & -0.10 & & 0.19 & 0.19 & 0.00 & \\
\hline West North Central & 0.20 & 0.09 & 0.10 & & 0.10 & 0.10 & 0.00 & \\
\hline South Atlantic & 0.23 & 0.41 & -0.18 & & 0.41 & 0.41 & 0.00 & \\
\hline East South Central & 0.02 & 0.05 & -0.03 & & 0.04 & 0.05 & -0.01 & \\
\hline West South Central & 0.17 & 0.07 & 0.11 & & 0.07 & 0.07 & 0.00 & \\
\hline Mountain & 0.09 & 0.12 & -0.04 & & 0.12 & 0.13 & -0.01 & \\
\hline Pacific & 0.08 & 0.04 & 0.04 & & 0.04 & 0.04 & 0.00 & \\
\hline Index drug group & & & & 0.03 & & & & 0.55 \\
\hline Cyclosporine & 0.03 & 0.03 & 0.00 & & 0.03 & 0.03 & -0.01 & \\
\hline Tacrolimus Anhydrous & 0.19 & 0.20 & -0.01 & & 0.24 & 0.20 & 0.04 & \\
\hline Mycophenolate Mofetil & 0.46 & 0.47 & -0.02 & & 0.49 & 0.48 & 0.01 & \\
\hline Cyclosporine, Modified & 0.19 & 0.15 & 0.04 & & 0.13 & 0.15 & -0.02 & \\
\hline Sirolimus & 0.07 & 0.04 & 0.02 & & 0.03 & 0.05 & -0.01 & \\
\hline Mycophenolate Sodium & 0.06 & 0.10 & -0.03 & & 0.08 & 0.09 & -0.01 & \\
\hline
\end{tabular}

demographics (age, gender, and geographical location), patients' baseline costs (medical and pharmacy), an indicator to reflect time of start of oral transplant agent within the previous year as a proxy for duration of therapy during baseline period, and baseline comorbidities using the Charlson Comorbidity Index, indicators for patients on dual therapy, and transplant complications within the baseline period. Additionally, the use of 6 separate transplant medications: cyclosporine, tacrolimus anhydrous, mycophenolate mofetil, modified cyclosporine, sirolimus, and mycophenolate sodium were also included in the matching (see Appendix C).$^{30}$ After matching, these primary factors were compared at baseline to assess the comparability of the 2 cohorts: total costs, medical costs, pharmacy costs, and resource utilization variables, including hospitalization, inpatient and outpatient hospital visits, and ER visits.

The analytic framework involved utilizing t-tests for continuous variables and chi-square tests for categorical variables to measure statistical differences between the means of the outcome measures in the 2 cohorts during the follow-up period. All outcomes were studied during the 1-year follow-up, including transplant-related complications, dialysis and nondialysis outcomes, and associated costs. The primary outcome of costs, including total costs, pharmacy costs, and medical costs, were compared using t-tests, given that the assumptions to use this test were met. ${ }^{22,31-33}$ All other outcomes, including transplant-related costs, resource utilization, and measures of adherence and persistence, were considered to be secondary 


\section{Managing Specialty Medication Services Through a Specialty Pharmacy Program: The Case of Oral Renal Transplant Immunosuppressant Medications}

\section{TABLE 2 Baseline Period Health Care Cost and Utilization Measures for Renal Transplant Patients ${ }^{\mathrm{a}}$}

\begin{tabular}{|c|c|c|c|c|c|c|c|c|}
\hline & \multicolumn{4}{|c|}{ Before Propensity Score Matching } & \multicolumn{4}{|c|}{ After Propensity Score Matching } \\
\hline & Retail $(1)^{b}$ & Specialty $(2)^{c}$ & Diff (1-2) & $P$ Value & Retail (3) & Specialty (4)c & Diff (3-4) & $P$ Value \\
\hline$\overline{\mathrm{N}}$ & 1,289 & 541 & & & 519 & 519 & & \\
\hline Total cost & 36,202 & 33,930 & 2,273 & 0.38 & 34,371 & 34,298 & 73 & 0.98 \\
\hline Medical cost & 23,964 & 21,352 & 2,612 & 0.31 & 21,602 & 21,738 & -136 & 0.96 \\
\hline Transplant-related medical cost & 17,818 & 15,715 & 2,103 & 0.35 & 16,964 & 15,967 & 997 & 0.72 \\
\hline Members. with ER visits & 0.36 & 0.32 & 0.04 & 0.14 & 0.36 & 0.32 & 0.04 & 0.17 \\
\hline ER visit count & 0.76 & 0.83 & -0.07 & 0.56 & 0.79 & 0.84 & -0.05 & 0.75 \\
\hline ER visit cost & 218 & 159 & 59 & 0.17 & 173 & 161 & 11.5 & 0.73 \\
\hline Members with transplant-related ER visits & 0.10 & 0.07 & 0.02 & 0.14 & 0.08 & 0.08 & 0.00 & 0.91 \\
\hline Transplant-related ER count & 0.12 & 0.10 & 0.02 & 0.36 & 0.09 & 0.10 & -0.02 & 0.54 \\
\hline Transplant-related ER cost & 42.04 & 18.15 & 23.90 & 0.04 & 38.97 & 17.85 & 21.11 & 0.10 \\
\hline Members with inpatient visits & 0.31 & 0.30 & 0.01 & 0.59 & 0.30 & 0.31 & -0.01 & 0.84 \\
\hline Inpatient count & 0.49 & 0.46 & 0.02 & 0.59 & 0.48 & 0.47 & 0.01 & 0.86 \\
\hline Inpatient cost & 9,872 & 9,613 & 259 & 0.85 & 9,982 & 9,726 & 256 & 0.88 \\
\hline Inpatient LOS & 3.07 & 2.68 & 0.38 & 0.31 & 3.14 & 2.75 & 0.39 & 0.37 \\
\hline Members with transplant-related inpatient visits & 0.36 & 0.34 & 0.02 & 0.54 & 0.35 & 0.35 & 0.00 & 0.91 \\
\hline Transplant-related inpatient count & 0.50 & 0.46 & 0.04 & 0.43 & 0.51 & 0.47 & 0.04 & 0.48 \\
\hline Transplant-related inpatient cost & 10,730 & 10,396 & 334 & 0.84 & 11,567 & 10,542 & 1,026 & 0.63 \\
\hline Transplant-related inpatient LOS & 3.29 & 2.87 & 0.42 & 0.32 & 3.48 & 2.94 & 0.54 & 0.29 \\
\hline Members with outpatient visits & 0.88 & 0.86 & 0.02 & 0.30 & 0.88 & 0.87 & 0.01 & 0.58 \\
\hline Outpatient visit count & 12.54 & 11.75 & 0.79 & 0.31 & 11.33 & 11.98 & -0.65 & 0.46 \\
\hline Outpatient visit cost & 9,628 & 8,158 & 1,470 & 0.30 & 8,096 & 8,373 & -277 & 0.86 \\
\hline Members with transplant-related outpatient visits & 0.81 & 0.80 & 0.02 & 0.60 & 0.82 & 0.81 & 0.01 & 0.69 \\
\hline Transplant-related outpatient visit count & 6.31 & 5.43 & 0.88 & 0.07 & 5.70 & 5.51 & 0.19 & 0.71 \\
\hline Transplant-related outpatient visit cost & 5,734 & 4,375 & 1,359 & 0.15 & 4,485 & 4,482 & 2.77 & 1.00 \\
\hline Members with office visits & 0.99 & 0.99 & 0.00 & 0.94 & 0.99 & 0.99 & 0.00 & 0.70 \\
\hline Office visit count & 16.94 & 15.01 & 1.92 & 0.01 & 15.48 & 15.10 & 0.39 & 0.64 \\
\hline Office visit cost & 2,664 & 2,060 & 604 & 0.04 & 2,171 & 2,093 & 77.78 & 0.77 \\
\hline Members with transplant-related office visits & 0.92 & 0.92 & 0.00 & 0.99 & 0.90 & 0.92 & -0.02 & 0.46 \\
\hline Transplant-related office visit count & 5.20 & 4.22 & 0.98 & 0.00 & 4.36 & 4.19 & 0.17 & 0.55 \\
\hline Transplant-related office visit cost & 668 & 435 & 233 & 0.01 & 484 & 440 & 43.78 & 0.62 \\
\hline Rx count & 66.30 & 66.81 & -0.51 & 0.80 & 64.55 & 66.75 & -2.21 & 0.35 \\
\hline $\mathrm{Rx}$ cost & 12,239 & 12,577 & -339 & 0.39 & 12,769 & 12,559 & 209 & 0.65 \\
\hline Transplant-related Rx count & 12.64 & 13.53 & -0.90 & 0.04 & 13.27 & 13.44 & -0.18 & 0.74 \\
\hline Transplant-related Rx cost & 7,289 & 8,012 & -723 & 0.01 & 7,960 & 7,920 & 39 & 0.90 \\
\hline
\end{tabular}

outcomes. The effects of the program on each of the measures of medication adherence were compared using t-tests. All tests were 2-tailed, with $P<0.05$ considered statistically significant. SAS version 9.1 (Carey, NC) was utilized for all statistical analyses.

\section{Results}

\section{Study Cohort Characteristics}

A total of 3,515 unique renal transplant patients who filled 1 or more oral transplant prescriptions between August 1, 2007, and December 31, 2007, were identified (Figure 2). After applying continuous enrollment and minimum filling inclusion criteria, 2,157 patients remained, of which 541 participated in the specialty pharmacy program. After subsequent propensity matching procedures, 519 patients remained in each of the specialty pharmacy and retail pharmacy cohorts, with no statistically significant differences at the 5\% level; in age, gender, geographic distribution; time since initiation of the medication; distribution of oral transplant therapy; oral transplant agent start dates during baseline using 90-day intervals; and pharmacy, medical, and total direct health care costs during the baseline period. The flowchart (Figure 2) illustrates the patient selection process, and Tables 1 and 2 summarize the matching and baseline evaluations. 


\section{Managing Specialty Medication Services Through a Specialty Pharmacy Program: The Case of Oral Renal Transplant Immunosuppressant Medications}

\section{TABLE 3 Follow-Up Period Health Care Outcomes of Propensity Score Matched Sample}

of Renal Transplant Patients ${ }^{a}$

\begin{tabular}{|c|c|c|c|c|c|c|}
\hline & \multicolumn{2}{|c|}{ Retail Pharmacy } & \multicolumn{2}{|c|}{ Specialty Pharmacy } & \multirow{2}{*}{$\begin{array}{l}\text { Difference in } \\
\text { Means }\end{array}$} & \multirow[b]{2}{*}{$P$ Value } \\
\hline & Mean & SD & Mean & SD & & \\
\hline $\mathrm{N}$ & 519.00 & & 519.00 & & & \\
\hline Weighted MPR & 0.83 & 0.20 & 0.87 & 0.15 & -0.04 & $<.0001$ \\
\hline Medication gap $(\mathrm{MG})^{\mathrm{b}}$ & 0.10 & & 0.06 & & 0.04 & 0.006 \\
\hline$[M G-(N)]$ & [53] & & [29] & & & \\
\hline Discontinuation (DC) & 0.20 & & 0.08 & & 0.12 & $<.0001$ \\
\hline$[D C-(N)]$ & {$[104]$} & & [39] & & & \\
\hline MG and/or DC & 0.27 & & 0.13 & & 0.15 & $<.0001$ \\
\hline [MG and/or DC-(N)] & {$[142]$} & & [65] & & & \\
\hline Total cost & 27,891 & 30,713 & 24,315 & 22,747 & 3,576 & 0.03 \\
\hline Medical cost & 13,194 & 27,945 & 10,605 & 20,144 & 2,589 & 0.09 \\
\hline Transplant-related medical cost & 8,486 & 23,682 & 5,960 & 15,565 & 2,525 & 0.04 \\
\hline Nondialysis related & 6,739 & 744 & 5,232 & 515 & 1,507 & 0.10 \\
\hline Dialysis related & 1,747 & 511 & 728 & 279 & 1,019 & 0.08 \\
\hline Members with ER visits & 0.34 & & 0.33 & & 0.01 & 0.79 \\
\hline ER visit count & 0.72 & 1.77 & 0.90 & 2.49 & -0.18 & 0.18 \\
\hline ER visit cost & 166 & 628 & 153 & 444 & 14 & 0.69 \\
\hline Members with transplant-related ER visits & 0.08 & & 0.08 & & 0.01 & 0.73 \\
\hline Transplant-related ER count & 0.10 & 0.38 & 0.11 & 0.45 & -0.01 & 0.71 \\
\hline Transplant-related ER cost & 20.75 & 114.20 & 21.80 & 142.10 & -1.05 & 0.90 \\
\hline Members with inpatient visits & 0.21 & & 0.21 & & 0.00 & 1.00 \\
\hline Inpatient count & 0.33 & 0.78 & 0.34 & 0.89 & -0.01 & 0.88 \\
\hline Inpatient cost & 4,529 & 15,978 & 3,156 & 10,623 & 1,373 & 0.10 \\
\hline Inpatient LOS & 2.24 & 7.22 & 1.90 & 6.28 & 0.34 & 0.42 \\
\hline Members with transplant-related inpatient visits & 0.24 & & 0.22 & & 0.02 & 0.56 \\
\hline Transplant-related inpatient count & 0.36 & 0.92 & 0.34 & 0.93 & 0.01 & 0.81 \\
\hline Transplant-related inpatient cost & 4,771 & 17,446 & 3,117 & 11,991 & 1,654 & 0.08 \\
\hline Transplant-related inpatient LOS & 2.44 & 8.37 & 2.02 & 8.03 & 0.42 & 0.41 \\
\hline Members with outpatient visits & 0.85 & & 0.83 & & 0.02 & 0.40 \\
\hline Outpatient visit count & 9.85 & 11.85 & 10.45 & 15.10 & -0.61 & 0.47 \\
\hline Outpatient visit cost & 5,037 & 11,951 & 4,178 & 8,821 & 859 & 0.19 \\
\hline Members with transplant-related outpatient visits & 0.71 & & 0.71 & & 0.00 & 0.95 \\
\hline Transplant-related outpatient visit count & 4.62 & 6.79 & 4.53 & 8.06 & 0.09 & 0.84 \\
\hline Transplant-related outpatient visit cost & 2,837 & 9,441 & 2,050 & 5,712 & 787 & 0.10 \\
\hline Members with office visits & 0.98 & & 0.99 & & 0.00 & 0.59 \\
\hline Office visit count & 14.60 & 13.34 & 14.85 & 13.62 & -0.25 & 0.76 \\
\hline Office visit cost & 2,330 & 5,613 & 2,029 & 4,091 & 301 & 0.32 \\
\hline Members with transplant-related office visits & 0.89 & & 0.90 & & 0.00 & 0.85 \\
\hline Transplant-related office visit count & 4.36 & 5.95 & 3.91 & 4.25 & 0.45 & 0.16 \\
\hline Transplant-related office visit cost & 555 & 1,538 & 395 & 952 & 160 & 0.04 \\
\hline Rx count & 67.20 & 37.51 & 72.37 & 37.40 & -5.17 & 0.03 \\
\hline Rx cost & 14,697 & 8,565 & 13,710 & 7,305 & 987 & 0.05 \\
\hline Transplant-related Rx count & 17.90 & 6.61 & 18.67 & 6.13 & -0.77 & 0.05 \\
\hline Transplant-related Rx cost & 9,991 & 5,754 & 9,244 & 5,525 & 747 & 0.03 \\
\hline
\end{tabular}

aStatistics are means unless otherwise stated.

${ }^{b} M G=G a p$ of 60 days or more between run-out date of an $R x$ and fill date of subsequent $R x$.

${ }^{c} D C=G a p$ of 60 days or more between run-out date of last $R x$ and end of follow-up period.

$E R=$ emergency room; $L O S=$ length of stay; $M P R=$ medication possession ratio; $R x=$ prescription; $S D=$ standard deviation.

\section{Comparison in the Follow-Up Period}

The comparison of follow-up costs, health care utilization measures, and weighted MPR between the matched specialty pharmacy program and retail cohort is presented in Table 3.
There were statistically significant differences between the 2 groups for the primary outcome measure and the total health care costs (the sum of pharmacy, outpatient, and inpatient medical costs). The mean total cost per patient in the 


\section{Managing Specialty Medication Services Through a Specialty Pharmacy Program: The Case of Oral Renal Transplant Immunosuppressant Medications}

TABLE 4 Follow-Up Period Dialysis- and Nondialysis-Related Medical Outcomes

\begin{tabular}{|c|c|c|c|c|c|c|}
\hline & \multicolumn{2}{|c|}{ Retail Pharmacy } & \multicolumn{2}{|c|}{ Specialty Pharmacy } & \multirow{2}{*}{$\begin{array}{l}\text { Difference } \\
\text { in Means }\end{array}$} & \multirow[b]{2}{*}{$P$ Value } \\
\hline & Mean & SD & Mean & SD & & \\
\hline $\mathrm{N}$ & 519 & & 519 & & & \\
\hline Members with dialysis-related ER visit & 0.01 & & 0.002 & & 0.01 & 0.15 \\
\hline Dialysis-related ER visit count & 0.01 & 0.09 & 0.002 & 0.04 & 0.01 & 0.18 \\
\hline Dialysis-related ER visit cost & 3.12 & 41.29 & 0.005 & 0.11 & 3.12 & 0.09 \\
\hline Members with nondialysis-related ER visit & 0.07 & & 0.07 & & 0.00 & 1.00 \\
\hline Nondialysis-related ER visit count & 0.09 & 0.37 & 0.10 & 0.45 & -0.02 & 0.55 \\
\hline Nondialysis-related ER visit cost & 17.63 & 106.40 & 21.80 & 142.10 & -4.17 & 0.59 \\
\hline Members with dialysis-related inpatient hospital stay & 0.04 & & 0.02 & & 0.02 & 0.05 \\
\hline Dialysis-related inpatient hospital count & 0.05 & 0.34 & 0.03 & 0.24 & 0.03 & 0.14 \\
\hline Dialysis-related inpatient hospital cost & 595 & 4,540 & 289 & 3,909 & 306 & 0.24 \\
\hline Dialysis-related inpatient hospital length of stay & 0.37 & 2.65 & 0.35 & 3.50 & 0.02 & 0.91 \\
\hline Members with nondialysis-related inpatient hospital stay & 0.20 & & 0.21 & & 0.00 & 0.88 \\
\hline Nondialysis-related inpatient hospital count & 0.30 & 0.71 & 0.32 & 0.81 & -0.01 & 0.78 \\
\hline Nondialysis-related inpatient hospital cost & 4,176 & 15,245 & 2,828 & 9,740 & 1,348 & 0.09 \\
\hline Nondialysis-related inpatient hospital length of stay & 2.07 & 6.92 & 1.67 & 5.34 & 0.40 & 0.30 \\
\hline Members with dialysis-related outpatient hospital visit & 0.05 & & 0.04 & & 0.01 & 0.54 \\
\hline Dialysis-related outpatient hospital visit count & 0.40 & 2.80 & 0.26 & 2.92 & 0.14 & 0.43 \\
\hline Dialysis-related outpatient hospital visit cost & 1,075 & 7,824 & 414 & 3,286 & 661 & 0.08 \\
\hline Members with nondialysis-related outpatient hospital visit & 0.66 & & 0.67 & & -0.01 & 0.74 \\
\hline Nondialysis-related outpatient hospital visit count & 4.23 & 6.17 & 4.27 & 6.97 & -0.05 & 0.91 \\
\hline Nondialysis-related outpatient hospital visit cost & 1,763 & 4,142 & 1,636 & 3,994 & 126 & 0.62 \\
\hline
\end{tabular}

first follow-up year was 13\% lower in the specialty pharmacy program group $(\$ 24,315$ vs. $\$ 27,891$, difference $=-\$ 3,576$; $P=0.03)$. Similarly, the mean transplant-related medical cost was $30 \%$ lower in the specialty pharmacy program group $(\$ 5,960$ vs. $\$ 8,486$, difference $=-\$ 2,525 ; P=0.04)$. Both nondialysis-related costs $(\$ 5,232$ vs. $\$ 6,739 ; P=0.10)$ and dialysisrelated costs ( $\$ 728$ vs. $\$ 1,747 ; P=0.08$ ) were lower in the specialty group, even though statistical significance was not reached. The mean number of oral transplant prescriptions dispensed per patient was higher in the specialty pharmacy program group than in the retail pharmacy group (18.67 vs. 17.90, respectively; difference $=-0.77 ; P<0.05$ ). Among secondary outcome measures, except for the mean transplantrelated office visit cost (difference $=\$ 160 ; P=0.04$ ) that was significantly lower in the specialty cohort, all other parameters were not significantly different between the two groups.

The weighted MPR for oral immunosuppressive therapy medications was higher in the specialty pharmacy program members than in the retail pharmacy members $(0.87$ vs. 0.83 , respectively; $P<0.0001$ ). The number of members with an MG was lower in the specialty group than in the retail group (29 vs. 53 , respectively; $P=0.006$ ). In addition, 39 patients in the specialty cohort discontinued the drug, compared with 104 patients in the retail cohort $(P<0.0001)$, and 65 patients in the specialty pharmacy cohort experienced either a gap or discontinuation, compared with 142 patients in the retail cohort $(P<0.0001)$.
Dialysis-related and nondialysis-related medical outcomes during the follow-up were also evaluated. There was a significant difference in the mean number of members with dialysis-related inpatient hospital stays between the two groups (0.02 vs. 0.04, $P=0.03$ ), leading to lower, although nonsignificant, mean dialysis-related inpatient hospital count and mean dialysis-related inpatient hospital costs in the specialty cohort. Outpatient resource utilization related to dialysis also trended lower in the specialty group (see Table 4 for details). Transplant complications were also evaluated, and no significant differences were found between the two groups during the follow-up period.

\section{Discussion}

As we expand coverage to patients in the United States while attempting to contain costs, it is essential to identify approaches that can improve quality while reducing the overall cost of care, especially in the commercial patient population. Studies have indicated positive outcomes in patients with multiple sclerosis (MS), human immunodeficiency virus (HIV)/acquired immunodeficiency syndrome (AIDS), oral oncology, and rheumatoid arthritis (RA) using specialty pharmacy services. In patients with MS, specialty services, including a disease therapy management program (DTM), improved medication adherence and persistence among participants compared with patients being followed in a nonspecialty setting. Medication adherence was improved in the settings of specialty pharmacy services alone 


\section{Managing Specialty Medication Services Through a Specialty Pharmacy Program: The Case of Oral Renal Transplant Immunosuppressant Medications}

and specialty pharmacy services with a DTM program compared with to retail pharmacy patients ( 0.90 and 0.92 vs. 0.86 , respectively). In patients with HIV/AIDS, specialized pharmacies have documented improvements in mean proportion of days covered (PDC) of $74.1 \%$ versus $69.2 \%$ in nonspecialty settings $(P<0.0001)$. Additionally, a greater percentage of patients in the specialty pharmacy group was able to obtain a PDC of $95 \%$ or better $(39.3 \%$ vs. $35.5 \%)$ and was significantly more persistent $(P=0.0117)$. For oral oncology patients, those in the specialty pharmacy group were more adherent as evidenced by a weighted MPR of 0.66 versus $0.58(P<0.001)$. In this study, the overall mean total costs per patient were 13\% lower, and mean outpatient costs were $41 \%$ lower in the specialty pharmacy group compared with the control groups during the follow-up period. In a study of RA patients, medication adherence to self-injectable RA medications for patients participating in a DTM plan as an enhancement to specialty pharmacy services were compared to patients receiving specialty pharmacy services without a DTM plan and to patients at community pharmacies. During the follow-up period, mean PDC was 0.83 for the specialty pharmacy with a DTM intent-to-treat population, 0.81 for specialty pharmacies without DTM, and 0.60 for community pharmacy patients (both $P<0.05$ compared with community pharmacy patients). Lastly, a study by Barlow et al. (2012) showed that, in addition to improvements in medication adherence, significant reduction in medical costs was documented for 3 years of participation in specialty pharmacy services versus retail pharmacy services for RA patients. ${ }^{22,34-38}$

Our findings suggest that specialty pharmacy programs can improve the management and medication adherence of patients with renal transplants and simultaneously reduce overall health care costs, which is similar to findings in previous studies. ${ }^{1,17,22,34-38}$ This study demonstrates the value of specialty pharmacy programs in improving adherence to oral transplant products in the first year post-implementation of the program. Substantial increases in several measures of adherence, including the number of oral transplant prescriptions filled and fewer gaps in therapy and discontinuation, were seen in patients who used the specialty pharmacy program in the first year. Importantly, the increases in MPR and in prescriptions in the specialty pharmacy group are not significantly associated with an increase in pharmacy costs. Rather, pharmacy costs are lower in the specialty pharmacy group. UnitedHealthcare Pharmacy has successfully negotiated program components of discounted transplant medication rates and services through the contracted specialty pharmacy to mitigate the effect of increased adherence contributing to higher immunosuppressive therapy medication costs.

Specialty pharmacy programs are associated with a $13 \%$ reduction in overall health care costs and a 30\% reduction in transplant-related medical costs, driven by decreases in both dialysis-related and nondialysis-related medical costs in this study. Additionally, the beneficial effect of specialty pharmacy on medical costs and medication adherence suggests that specialty pharmacy services may be impacting adherence- related improvements in quality of care. There are several possibilities as to why patients may have exhibited greater medication adherence in the specialty pharmacy arm. Specialty pharmacies improve education regarding medications, provide frequent reminders to take prescribed therapies, deliver positive reinforcements from a care manager, and provide directed management of expected adverse medication effects. Additionally, members in the specialty pharmacy program only receive a 30-day supply of medication at each fill versus a 90-day supply, which is normal for many chronic conditions.

Other possible explanations for better medication adherence in the specialty pharmacy group include better and earlier management of adverse events and comorbid conditions that may occur in the presence of systemic immunosuppression. In the specialty pharmacy group, patients are actively managed by clinical pharmacists who are trained to identify and remediate medication adverse effects as they occur in order to reduce rates and complexity of inpatient, outpatient, and office visits for these complaints, resulting in potentially reduced medical costs for these patients. Although not significant, there was a decreased number of inpatient visits and length of stays, as well as a lower number of transplant-related outpatient and office visits, all of which led to significant decreases in overall medical costs and transplant-related medical costs. The educational component of specialty pharmacy care and the 24/7 availability of a specialty-trained clinical pharmacist in combination with a highly responsive case management team may play an important role in improving health care efficiency.

\section{Limitations}

There are several important limitations to this study. Confounding may have resulted from selection bias, as patients or employers may have self-selected into either the specialty or retail pharmacy benefit programs. Approximately 13\% of the possible sample was omitted from the analytic dataset because these patients did not fill $80 \%$ of their prescriptions at either retail or specialty pharmacies. Of this $13 \%$, further analysis revealed that approximately $90 \%$ of the omitted population had their first script filled at the contracted pharmacy at least 90 days after the index date; $75 \%$ of them filled in the second or third quarter, meaning they were new patients who started later within the study period and may have been covered within their medical benefit plans prior to the change. There are several possibilities as to why patients may have filled their prescriptions through both channels for longer periods of time. The most likely possibility is that self-insured employers may have changed their preferred pharmacy outlets during the course of the study period, in which case patient selection would not have influenced pharmacy choice. After omitting these patients (13\%) from the sample, we examined whether or not patients within each employer group chose the same channels. We found variability in pharmacy choice within only 3\% of employers groups, which indicates that the overwhelming majority of beneficiaries included in this analysis used the preferred pharmacy channels of their employers. This finding 


\section{Managing Specialty Medication Services Through a Specialty Pharmacy Program: The Case of Oral Renal Transplant Immunosuppressant Medications}

limits the possibility that selection bias influenced our study results.

There also may have been confounding related to higher severity of disease and/or comorbid conditions or time from transplant; sicker patients may have differentially chosen one type of pharmacy over the other. There is no way to fully adjust for these characteristics with the use of claims data alone..$^{39-41}$ We would not expect a strong relationship between employer group and higher comorbidity and do not consider this to be an important source of confounding. Nevertheless, we attempted to address this issue by matching on multiple variables that served as a proxy for disease severity, including the Charlson Comorbidity Index score, time from start of immunosuppressive therapy truncated at 1 year, transplant complications during the baseline year, and patients on dual therapy during the baseline year.

Time post-transplant is a strong predictor of resource utilization, with costs decreasing over time. ${ }^{42-44}$ We do not have that data field in our retrospective claims, which may influence comparison of medical utilization and costs. Specialty and retail cohorts were balanced for new users to therapy using transplant medication claims (4\% and 3\%, respectively) and number of patients with first transplant medication claims during days 1-90, 91-180, 181-270, and 271 onward during the index period, but $\geq 84 \%$ of patients were on medication at the beginning of the index period and potentially prior to the baseline period as well. There is no way of fully determining time post-transplant for each patient due to health plan switches that the patient may go through and lack of visibility to full member claim history if they were previously with another health plan. Without matching specifically on time post-transplant, we implemented the one-on-one greedy matching technique to derive the propensity score matchedpairs to ensure similar demographics, utilization, and baseline costs between patients in both cohorts. Also, estimating adherence using a retrospective data analysis study design does not always give an accurate representation whether the medication was taken exactly as prescribed. It only gives us information on how much of the medication was filled versus how much was actually ingested by the patient.

Due to the retrospective nature of the study, we were not able to capture how consistently and how many patients participated in the pharmacy consultations on an ongoing basis monthly and every 3 months. We also did not capture or account for any additional services the patients may have received either through their pharmacies, physicians, hospitals, or insurance-based care management programs, although we assumed they might have existed in both groups. Finally, we also were not able to capture quality of life measures in this study, which would have provided information from a patient perspective and may have had significant policy implications.

\section{Conclusions}

These findings highlight the important role that specialty pharmacy programs with set requirements for clinical programs, services, and optimal contracted rates can play in improving adherence, the quality of care, and reducing the overall costs of patients with complex and costly conditions. Specialty clinical pharmacists appear to better coordinate care and reduce unnecessary medical costs in patients with renal transplantation, improving effectiveness and outcomes. Long-term evaluations after the first year are now being conducted to determine if these positive results are maintained.

The positive impact of health plan program design, coordinated care, and oversight by specialty-trained clinicians in a specialty pharmacy program has implications for the current health care reform and requires more research.

\section{Authors}

SUZANNE TSCHIDA, PharmD, BCPS, is Vice President, and BRETT SAHLI, PharmD, is Manager, Specialty Benefits \& Outcomes Strategy, OptumRx, Eden Prairie, Minnesota. SAAD ASLAM, PhD, is Managing Consultant, OptumInsight, Rocky Hill, Connecticut; TANVIR T. KHAN, MS, is Director, Pharmacy Analytics, Cigna, Bloomfield, Connecticut; WILLIAM H. SHRANK, MD, MSHS, is Assistant Professor of Medicine, Division of Pharmacoepidemiology and Pharmacoeconomics, Department of Medicine, Brigham and Women's Hospital, Harvard Medical School, Boston, Massachusetts; and LINCY S. LAL, PhD, PharmD, is Instructor, University of Texas School of Public Health, Houston, Texas.

AUTHOR CORRESPONDENCE: Saad Aslam, PhD, OptumInsight, CT040-001B, 400 Capital Blvd., Rocky Hill, CT 06067. Tel: 860221-0325; E-mail: saad.aslam@optum.com.

\section{DISCLOSURES}

Research for and the writing of this article was funded by United Healthcare Pharmacy.

Tschida was responsible for most of the concept and design with help from all of the authors. Aslam was responsible for most of the data collection with the help of Khan. All authors contributed to data interpretation and revision, and Lal, Sahli, Khan, Shrank, and Aslam were responsible for the writing.

\section{REFERENCES}

1. Chisholm-Burns MA, Spivey CA, Garrett C, McGinty H, Mulloy LL. Impact of clinical pharmacy services on renal transplant recipients' adherence and outcomes. Patient Prefer Adherence. 2008;2:287-92.

2. Butler JA, Roderick P, Mullee M, Mason JC, Peveler RC. Frequency and impact of nonadherence to immunosuppressants after renal transplantation: a systematic review. Transplantation. 2004;77(5):769-76.

3. Greenstein S, Siegal B. Compliance and noncompliance in patients with a functioning renal transplant: a multicenter study. Transplantation. 1998;66(12):1718-26

4. Chisholm MA, Vollenweider LJ, Mulloy LL, et al. Renal transplant patient compliance with free immunosuppressive medication. Transplantation. 2000;70(8):1240-44. 


\section{Managing Specialty Medication Services Through a Specialty Pharmacy Program: The Case of Oral Renal Transplant Immunosuppressant Medications}

5. Chisholm MA, Mulloy LL, DiPiro JT. Comparing renal transplant patients' adherence to free cyclosporine and free tacrolimus immunosuppressant therapy. Clin Transplant. 2005;19(1):77-82.

6. Bullington P, Pawola L, Walker R, Valenta A, Briars L, John E. Identification of medication nonadherence factors in adolescent transplant patients: the patient's viewpoint. Pediatr Transplant. 2007;11(8):914-21.

7. Dobbels F, Ruppar T, De Geest S, Decorte A, Van Damme-Lombaerts R, Fine $\mathrm{RN}$. Adherence to the immunosuppressive regimen in pediatric kidney transplant recipients: a systematic review. Pediatr Transplant. 2010;14(5):603-13.

8. Couzi L, Moulin B, Morin MP, et al. Factors predictive of medication nonadherence after renal transplantation: a French observation study. Transplantation. 2013;95(2):326-32.

9. Schmid-Mohler G, Thut MP, Wüthrich RP, Denhaerynck K, De Geest S. Nonadherence to immunosuppressive medication in renal transplant recipients within the scope of the Integrative Model of Behavioral Prediction: a cross-sectional study. Clin Transplant. 2010;24(2):213-22.

10. Delucchi A, Gutierrez H, Arrellano P, Slater C, Meneses M, López I. Factors that influence nonadherence in immunosuppressant treatment in pediatric transplant recipients: a proposal for an educational strategy. Transplant Proc. 2008;40(9):3241-43.

11. Pinsky BW, Takemoto SK, Lentine KL, et al. Transplant outcomes and economic costs associated with patient noncompliance to immunosuppression. Am J Transplant. 2009;9(11):2597-606.

12. Yen EF, Hardinger K, Brennan DC, et al. Cost-effectiveness of extending Medicare coverage of immunosuppressive medications to the life of a kidney transplant. Am J Transplant. 2004;4(10):1703-08.

13. Takemoto SK, Pinsky BW, Schnitzler MA, et al. A retrospective analysis of immunosuppression compliance, dose reduction, and discontinuation in kidney transplant recipients. Am J Transplant. 2007;7(12):2704-11.

14. Hansen R, Seifeldin R, Noe L. Medication adherence in chronic disease: issues in posttransplant immunosuppression. Transplant Proc. 2007;39(5):1287-300.

15. Ruppar TM, Russell CL. Medication adherence in successful kidney transplant recipients. Prog Transplant. 2009;19(2):167-72.

16. Farney AC, Doares W, Kaczmorksi S, Rogers J, Stratta RJ. Cost-effective immunosuppressive options for solid organ transplantation: a guide to lower cost for the renal transplant recipient in the USA. Immunotherapy. 2010;2(6):879-88.

17. DaVanzo JE, Dobson A, Kirby T. Assessing the cost of dispensing immunosuppressive drugs to Medicare Transplant Recipients—an update. A report prepared for the Transplant Pharmacy Coalition by The Lewin Group. CMS-2008-0073-0673.3. April 15, 2007. Available at: http://www.regulations. gov/contentStreamer?objectId $=0900006480 \mathrm{ca} 477 \mathrm{f} \&$ disposition $=$ attach ment\&contentType=pdf. Accessed January 30, 2013.

18. Vanscoy G. The emergence of specialty pharmacy. J Manag Care Pharm 2000;6(4):280-84.

19. Cohen SM, Kwasny MJ, Ahn J. Use of specialty care versus standard retail pharmacies for treatment of hepatitis C. Ann of Pharmacother. 2009:43:202-09.

20. Morisky DE, Green LW, Levine DM. Concurrent and predictive validity of a self-reported measure of medication adherence. Med Care. 1986;24(1):67-74

21. Merion RM, Ashby VB, Wolfe RA, et al. Deceased-donor characteristics and the survival benefit of kidney transplantation. JAMA. 2005;294(21): 2726-33.

22. Tschida SJ, Aslam S, Lal LS, et al. Outcomes of a specialty pharmacy program for oral oncology medications. Am J Pharm Benefits. 2012:4(4):165-74.

23. Rosenbaum PR, Rubin D. The central role of the propensity score in observational studies for causal effects. Biometrika. 1983;70(1):41-55.

24. Dehejia RH, Vahba S. Propensity score-matching methods for nonexperimental causal studies. Rev Econ Stat. 2002;84(1):151-61.
25. Zhao Z. Using matching to estimate treatment effects: data requirements, matching metrics, and monte carlo evidence. Rev Econ Stat. 2004;86(1):91-107.

26. Heckman JJ, Navarro-Lozano S. Using matching, instrumental variables and control functions to estimate economic choice models. NBER Working Paper. No. 9497. February 2003. Available at: http://ideas.repec.org/p/nbr/ nberwo/9497.html. Accessed January 21, 2013.

27. Card D, Krueger AB. Minimum wages and employment: a case study of the fast-food industry in New Jersey and Pennsylvania. Am Econ Rev. 1994:84(4):772-93.

28. Fu AZ, Dow WH, Liu G. Propensity score and difference-in-difference methods: a study of second-generation antidepressant use in patients with bipolar disorder. Health Serv Outcomes Res Methodol. 2007;7(1-2):23-38.

29. Parsons LS. Reducing bias in a propensity score matched-pair sample using greedy matching techniques. Paper presented at: SAS User Group International (SUGI 26) Conference, April 22-25, 2001; Long Beach, CA. Paper 214-26. Available at: http://www2.sas.com/proceedings/sugi26/p21426.pdf. Accessed January 21, 2013.

30. Charlson ME, Pompei P, Ales KL, MacKenzie CR. A new method of classifying prognostic comorbidity in longitutional studies: development and validation. J Chron Dis. 1987;40(5):373-83.

31. Elliott RA, Davies LM, Payne K, Moore JK, Harper NJ. Costing day case anesthesia: obtaining accurate patient-based costs for adults and children. Int J Technol Assess Health Care. 2004;20(4):552-61.

32. Barber JA, Thompson SG. Analysis of cost data in randomized trials: an application of the non-parametric bootstrap. Stat Med. 2000;19(23):3219-36.

33. Thompson SG, Barber JA. How should cost data in pragmatic randomized trials be analysed? BMJ. 2000;320(7243):1197-1200.

34. Stockl KM, Shin JS, Gong S, Harada AS, Solow BK, Lew HC. Improving patient self-management of multiple sclerosis through a disease therapy management program. Am J Manag Care. 2010;16(2):139-44.

35. Tan H, Yu J, Tabby D, et al. Clinical and economic impact of a specialty care management program among patients with multiple sclerosis: a cohort study. Mult Scler. 2010;16(8):956-63.

36. Murphy P, Cocohoba J, Tang A, et al. Impact of HIV-specialized pharmacies on adherence and persistence with antiretroviral therapy. AIDS Patient Care STDS. 2012;26(9):526-31.

37. Stockl KM, Shin JS, Lew HC, et al. Outcomes of a rheumatoid arthritis disease therapy management program focusing on medication adherence. J Manag Care Pharm. 2010;16(8):593-604.

38. Barlow JF, Faris RJ, Wang W, et al. Impact of specialty pharmacy on treatment costs for rheumatoid arthritis. Am J Pharm Benefits. 2012;(Special Issue):SP49-SP56

39. Shafazand S, Yang Y, Amore E, et al. A retrospective, observational cohort analysis of a nationwide database to compare heart failure prescriptions and related health care utilization before and after publication of updated treatment guidelines in the United States. Clin Ther. 2010;32(9):1642-50

40. Hepke KL, Martus MT, Share DA. Costs and utilization associated with pharmaceutical adherence in a diabetic population. Am J Manag Care. 2004;10(2):144-51.

41. Berger ML, Mamdani M, Atkins D, et al. Good research practices for comparative effectiveness research: defining, reporting, and interpreting nonrandomized studies of treatment effects using secondary data sources: the ISPOR good research practices for retrospective database analysis task force report-Part 1. Value Health. 2009;12(8):1044-52.

42. Moghani Lankarani M, Noorbala MH, Assari S. Causes of re-hospitalization in different post kidney transplantation periods. Ann Transplant. 2009;14(4):14-19.

43. Hagenmeyer EG, Haussler B, Hempel E, et al. Resource use and treatment costs after kidney transplantation: impact of demographic factors, comorbidities, and complication. Transplantation. 2004;77(10):1545-50.

44. Khan S, Tighiouart H, Kalra A, et al. Resource utilization among kidney transplant recipients. Kidney Int. 2003;64(2):657-64. 


\section{Managing Specialty Medication Services Through a Specialty Pharmacy Program: The Case of Oral Renal Transplant Immunosuppressant Medications}

\section{APPENDIX A Codes to Identify Transplant-Related Claims/Costs}

Diagnosis Codes (ICD-9-CM Dx):

\begin{tabular}{l|l}
\hline V42.0 & Organ or tissue replaced by transplant, kidney
\end{tabular}

996.81 Complications of transplanted organ, kidney

V58.44 Aftercare following organ transplant

E878.0 Surgical operation with transplant of whole organ as the cause of abnormal reaction of patient, or of later complication, without mention of misadventure at the time of operation

E878.4 Other restorative surgery (Note: used for partial organ transplant)

E933.1 Antineoplastic and immunosuppressive drugs causing adverse effects in therapeutic use

(Dialysis-Related Diagnosis Codes)

996.1 Mechanical complication of other vascular device, implant, and graft

996.56 Mechanical complication due to peritoneal dialysis catheter

996.62 Infection and inflammatory reaction due to vascular device, implant, and graft

996.68 Infection and inflammatory reaction due to peritoneal dialysis catheter

996.73 Other complications due to renal dialysis device, implant, and graft

V45.11 Renal dialysis status

V45.12 Noncompliance with renal dialysis

\begin{tabular}{l|l}
\hline V56.0 & Encounter for extracorporeal dialysis
\end{tabular}

V56.1 Encounter for fitting and adjustment of extracorporeal dialysis catheter

V56.2 $\quad$ Encounter for fitting and adjustment of peritoneal dialysis catheter

V56.31 $\quad$ Encounter for adequacy testing for hemodialysis

V56.32 Encounter for adequacy testing for peritoneal dialysis

\begin{tabular}{l|l}
\hline V56.8 & Encounter for other dialysis
\end{tabular}

E870.2 Accidental cut, puncture, perforation, or hemorrhage during kidney dialysis or other perfusion

E871.2 Foreign object left in body during kidney dialysis or other perfusion

E872.2 Failure of sterile precautions during kidney dialysis or other perfusion

E874.2 Mechanical failure of instrument or apparatus during kidney dialysis or other perfusion

E879.1 Kidney dialysis, without mention of misadventure at the time of procedure, as the cause of abnormal reaction of patient, or of later complication

Procedure Codes (ICD-9CM Px):

\begin{tabular}{l|l}
\hline 00.91 & Transplant from live related donor \\
\hline 00.92 & Transplant from live
\end{tabular}

00.92 Transplant from live nonrelated donor

00.93 Transplant from cadaver

55.53 Removal of transplanted or rejected kidney

$55.61 \quad$ Renal autotransplantation

\begin{tabular}{l|l}
\hline 55.69 & Other kidney transplantation
\end{tabular}

\begin{tabular}{l|l}
\hline 55.6 & Kidney transplantation
\end{tabular}

(Dialysis-Related Procedure Codes)

\begin{tabular}{l|l}
\hline 38.95 & Venous catheterization for renal dialysis \\
\hline 39.27 & Arterionostomy
\end{tabular}

\begin{tabular}{l|l}
39.27 & Arteriovenostomy for renal dialysis \\
\hline 39.42 & Revision of
\end{tabular}

39.42 Revision of arteriovenous shunt for renal dialysis

39.43 Removal of arteriovenous shunt for renal dialysis

39.93 Insertion of vessel-to-vessel cannula

39.94 Replacement of vessel-to-vessel cannula

39.95 Hemodialysis

54.93 Creation of cutaneoperitoneal fistula

$54.98 \quad$ Peritoneal dialysis

CPT Codes

00862 (Anesthesia for) renal procedure/donor nephrectomy

00868 (Anesthesia for) renal transplant (recipient)

01990 Physiological support of harvesting organs from brain-dead patient

36251 Selective catheter placement (first-order), main renal artery and any accessory renal artery for renal angiography, including arterial puncture and catheter placement(s), fluoroscopy, contrast injection(s), image post-processing, permanent recording of images, and radiological supervision and interpretation, including pressure gradient measurements when performed, and flush aortogram when performed; unilateral

36252 Selective catheter placement (first-order), main renal artery and any accessory renal artery for renal angiography, including arterial puncture and catheter placement(s), fluoroscopy, contrast injection(s), image post-processing, permanent recording of images, and radiological supervision and interpretation, including pressure gradient measurements when performed, and flush aortogram when performed; bilateral 


\section{Managing Specialty Medication Services Through a Specialty Pharmacy Program: The Case of Oral Renal Transplant Immunosuppressant Medications}

\section{APPENDIX A Codes to Identify Transplant-Related Claims/Costs (continued)}

angiography, including arterial puncture, catheterization, fluoroscopy, contrast injection(s), image post-processing, permanent recording of images, and radiological supervision and interpretation, including pressure gradient measurements when performed, and flush aortogram when performed; unilateral

36254 Superselective catheter placement (one or more second order or higher renal artery branches) renal artery and any accessory renal artery for renal angiography, including arterial puncture, catheterization, fluoroscopy, contrast injection(s), image post-processing, permanent recording of images, and radiological supervision and interpretation, including pressure gradient measurements when performed, and flush aortogram when performed; bilateral

$50300 \quad$ Removal of donor kidney from cadaver donor

$50320 \quad$ Removal of donor kidney from living donor

50323 Backbench standard preparation cadaver donor renal allograft

50325 Backbench standard preparation living donor renal allograft open or laparoscopic

50327 Backbench reconstruction of cadaver or living donor renal allograft

50328 Backbench reconstruction of donor renal allograft; arterial anastomosis, each

50329 Backbench reconstruction of donor renal allograft; ureteral anastomosis, each

50340 Removal of kidney

50360 Transplantation of kidney

50365 Renal allotransplantation, implantation of graft

$50370 \quad$ Remove transplanted kidney

50380 Reimplantation of kidney

50547 Lap remove donor kidney

(Dialysis-Related CPT Codes)

\begin{tabular}{l|ll}
36147 & Introduction of needle and/or catheter, arteriovenous shunt created for dialysis (graft/fistula); initial access with complete radiological evaluation of
\end{tabular} dialysis access, including fluoroscopy, image documentation and report (includes access of shunt, injection(s) of contrast, and all necessary imaging from the arterial anastomosis and adjacent artery through entire venous outflow including the inferior or superior vena cava

36148 Introduction of needle and/or catheter, arteriovenous shunt created for dialysis (graft/fistula); additional access for therapeutic intervention

$36800 \quad$ Insertion of cannula for hemodialysis, other purpose (separate procedure); vein to vein

$36810 \quad$ Insertion of cannula for hemodialysis, other purpose (separate procedure); arteriovenous, external (Scribner type)

36815 Insertion of cannula for hemodialysis, other purpose (separate procedure); arteriovenous, external revision or closure

36818 Arteriovenous anastomosis, open; by upper arm cephalic vein transposition

36819 Arteriovenous anastomosis, open; by upper arm basilic vein transposition

36820 Arteriovenous anastomosis, open; by forearm vein transposition

36821 Arteriovenous anastomosis, open; direct, any site (e.g., Cimino type) (separate procedure)

36831 Thrombectomy, open, arteriovenous fistula without revision, autogenous or nonautogenous dialysis graft (separate procedure)

36832 Revision, open, arteriovenous fistula; without thrombectomy, autogenous or nonautogenous dialysis graft (separate procedure)

36833 Revision, open, arteriovenous fistula; with thrombectomy, autogenous or nonautogenous dialysis graft (separate procedure)

36835 Insertion of Thomas shunt (separate procedure)

36838 Distal revascularization and internal ligation (DRILL), upper extremity hemodialysis access (steal syndrome)

$36860 \quad$ External cannula declotting (separate procedure); without balloon catheter

$36861 \quad$ External cannula declotting (separate procedure); with balloon catheter

36870 Thrombectomy, percutaneous, arteriovenous fistula, autogenous or nonautogenous graft (includes mechanical thrombus extraction and intra-graft thrombolysis)

90935 Hemodialysis procedure with single physician evaluation

90937 Hemodialysis procedure requiring repeated evaluation(s) with or without substantial revision of dialysis prescription

90940 Hemodialysis access flow study to determine blood flow in grafts and arteriovenous fistulae by an indicator method

90945 Dialysis procedure other than hemodialysis (e.g., peritoneal dialysis, hemofiltration, or other continuous renal replacement therapies) with single physician evaluation

90947 Dialysis procedure other than hemodialysis (e.g., peritoneal dialysis, hemofiltration, or other continuous renal replacement therapies) requiring repeated physician evaluations, with or without substantial revision of dialysis prescription

HCPCS Codes

$\mathrm{C} 1750 \quad$ Catheter, hemodialysis/peritoneal, long-term

C1752 Catheter, hemodialysis/peritoneal, short-term

J7500 Azathioprine, oral, $50 \mathrm{mg}$

J7501 Azathioprine, parenteral, $100 \mathrm{mg}$

J7502 Cyclosporine, oral, $100 \mathrm{mg}$

J7504 Lymphocyte immune globulin, antithymocyte globulin, equine, parenteral, $250 \mathrm{mg}$

\begin{tabular}{l|l}
\hline $\mathrm{J} 7505$ & Muromonab-cd3, parenteral, $5 \mathrm{mg}$ \\
\hline
\end{tabular}

J7506 Prednisone, oral, per $5 \mathrm{mg}$ 


\section{Managing Specialty Medication Services Through a Specialty Pharmacy Program: The Case of Oral Renal Transplant Immunosuppressant Medications}

\section{APPENDIX A Codes to Identify Transplant-Related Claims/Costs (continued)}

\begin{tabular}{|c|c|}
\hline $\mathrm{J} 7507$ & Tacrolimus, oral, per $1 \mathrm{mg}$ \\
\hline $\mathrm{J} 7509$ & Methylprednisolone oral, per $4 \mathrm{mg}$ \\
\hline $\mathrm{J} 7510$ & Prednisolone oral, per $5 \mathrm{mg}$ \\
\hline $\mathrm{J} 7511$ & Lymphocyte immune globulin, antithymocyte globulin, rabbit, parenteral, $25 \mathrm{mg}$ \\
\hline $\mathrm{J} 7513$ & Daclizumab, parenteral, $25 \mathrm{mg}$ \\
\hline $\mathrm{J} 7515$ & Cyclosporine, oral, $25 \mathrm{mg}$ \\
\hline $\mathrm{J} 7516$ & Cyclosporin, parenteral, $250 \mathrm{mg}$ \\
\hline $\mathrm{J} 7517$ & Mycophenolate mofetil, oral, $250 \mathrm{mg}$ \\
\hline $\mathrm{J} 7518$ & Mycophenolic acid, oral, $180 \mathrm{mg}$ \\
\hline $\mathrm{J} 7520$ & Sirolimus, oral, $1 \mathrm{mg}$ \\
\hline $\mathrm{J} 7525$ & Tacrolimus, parenteral, $5 \mathrm{mg}$ \\
\hline $\mathrm{J} 7599$ & Immunosuppressive drug, not otherwise classified \\
\hline $\mathrm{Q} 0510$ & Pharmacy supply fee for initial immunosuppressive drug(s), first month \\
\hline Q0510 & Following transplant \\
\hline Q0511 & Pharmacy supply fee for oral anticancer, oral anti-emetic, or immunosuppressive \\
\hline Q0511 & Drug(s), for the first prescription, in a 30-day period \\
\hline $\mathrm{Q} 0512$ & Pharmacy supply fee for oral anti-cancer, oral anti-emetic, or immunosuppressive \\
\hline Q0512 & Drug(s), for a subsequent prescription, in a 30-day period \\
\hline $\mathrm{S} 2152$ & Solid organ(s), complete or segmental, single organ, or combination of organs \\
\hline $\mathrm{S} 2152$ & Deceased or living donor(s), procurement, transplantation, and related complications \\
\hline $\mathrm{S} 2152$ & Complications, including: drugs, supplies, hospitalization with outpatient \\
\hline $\mathrm{S} 2152$ & Follow-up: medical/surgical, diagnostic, emergency, and rehabilitative \\
\hline $\mathrm{S} 2152$ & Services and the number of days of pre- and post-transplant care in the global definition \\
\hline$\underline{S 2152}$ & Definition \\
\hline S9975 & Transplant-related lodging, meals, and transportation, per diem \\
\hline
\end{tabular}

\begin{tabular}{l|c|c}
\hline \multicolumn{2}{c}{ APPENDIX B List of Transplant Drugs } \\
\hline HICL & HICL Description & Brand Namea $^{\mathrm{a}}$ \\
\hline 004524 & Cyclosporine & Cyclosporine \\
\hline 004524 & Cyclosporine & Sandimmune \\
\hline 008974 & Tacrolimus Anhydrous & Prograf \\
\hline 010012 & Mycophenolate Mofetil & Cellcept \\
\hline 010086 & Cyclosporine, Modified & Cyclosporine \\
\hline 010086 & Cyclosporine, Modified & Gengraf \\
\hline 010086 & Cyclosporine, Modified & Neoral \\
\hline 020519 & Sirolimus & Rapamune \\
\hline 025201 & Mycophenolate Sodium & Myfortic \\
\hline
\end{tabular}

a Brand names listed are for informational purposes only. No promotion or marketing of any kind is implied.

$\mathrm{HICL}=$ Hierarchical Ingredient Code Listing 


\section{Managing Specialty Medication Services Through a Specialty Pharmacy Program: The Case of Oral Renal Transplant Immunosuppressant Medications}

\section{APPENDIX C Weighted Medication Possession Ratio Methodology}

A weighted medication possession ratio (MPR) methodology is used in this study. Weighted MPR is a measure of adherence that takes into account switching, augmentation, as well as concomitant use of medications. Two example calculations of weighted MPR are included below.

In the first example, the patient augments therapy but does not switch therapy at any time during follow-up. Assume a patient with the following prescription fill pattern. Assume patient takes Med 1, Med 2, and Med 3 during follow-up period.

\begin{tabular}{|c|c|c|c|c|}
\hline Day & 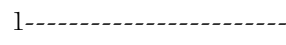 & 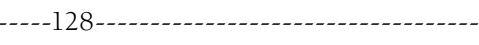 & 50--------- & -------365 \\
\hline Med 1 & $* * * * * * * * * * * * * * * * * * *$ & $* * * * * * * * * * \quad * * * * * * * * * *$ & $* * * * * * * * * *$ & $* * * * * * * * * *$ \\
\hline Med 2 & & $* * * * * * * * * * * * * * * * * * * * * * * * * * * * * *$ & $* * * * * * * * * *$ & $* * * * * * * * * *$ \\
\hline Med 3 & & & $* * * * * * * * * *$ & $* * * * * * * * * *$ \\
\hline
\end{tabular}

First, MPR is calculated for each medication individually, where MPR = days' supply received from the date of the first fill of that medication until the end of the review period divided by the number of days from the first fill of that medication until the end of the review period. Assuming that each $* * * * * * * * *$ in the diagram above represents a 30-day supply, individual MPR values are:

- Med 1: $180 / 365=0.493$

- Med 2: $150 / 238=0.630$

- Med 3: $60 / 116=0.517$

Average MPR is then calculated during each period of unique therapy. In the example above, the patient received:

- Days 1-127 (127 days): Med 1 only; MPR=0.493

- Days 128-249 (122 days): Med 1 and Med 2; MPR $=(0.493+0.630) / 2=0.561$

- Days 250-365 (116 days): Med 1, Med 2, and Med 3; MPR $=(0.493+0.630+0.517) / 3=0.547$

Weighted MPR is then calculated as: $\left(\frac{127}{365} \times 0.493\right)+\left(\frac{122}{365} \times 0.561\right)+\left(\frac{116}{365} \times 0.547\right)=0.533$

In the second example, the patient augments and switches therapy during follow-up. Assume a patient with the following prescription fill pattern.

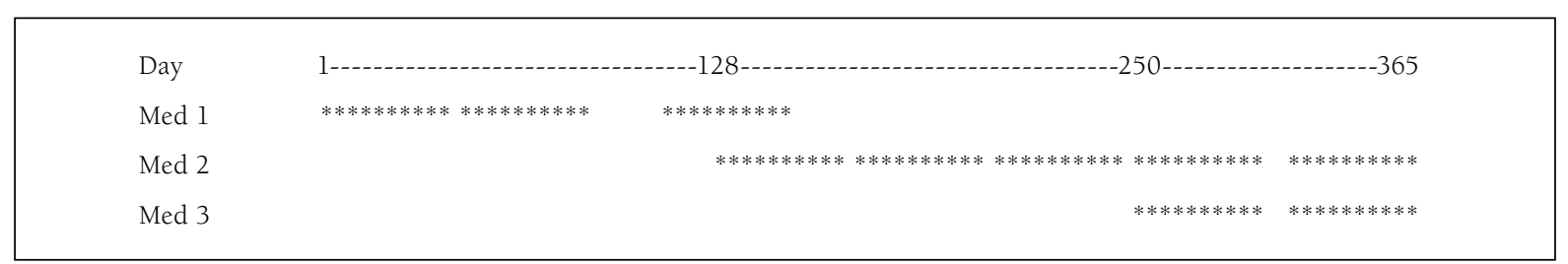

First, MPR is calculated for each medication individually. If no switch in therapy is noted, MPR=days' supply received from the date of the first fill of that medication until the end of the review period divided by the number of days from the first fill of that medication until the end of the review period. Note that in this example, the patient switched from Med 1 to Med 2 and then added Med 3 to ongoing Med 2 therapy. Therefore, for Med 1, MPR=days' supply received from the date of the first fill of Med 1 until the date of the first fill of Med 2 (truncated if necessary) divided by the number of days from the first fill of Med 1 until the date of the first fill of Med 2.

Assuming that each $* * * * * * * * * *$ in the diagram above represents a 30 -day supply, individual MPR values are:

- Med 1: $68 / 127=0.535$

- Med 2: $150 / 238=0.630$

- Med 3: $60 / 116=0.517$

Average MPR is then calculated during each period of unique therapy. In the example above, the patient received:

- Days 1-127 (127 days): Med 1 only; MPR=0.535

- Days 128-249 (122 days): Med 2 only; MPR=0.630

- Days 250-365 (116 days): Med 2 and Med 3; MPR $=(0.630+0.517) / 2=0.573$

Weighted MPR is then calculated as: $\left(\frac{127}{365} \times 0.535\right)+\left(\frac{122}{365} \times 0.630\right)+\left(\frac{116}{365} \times 0.573\right)=0.579$ 